\title{
Uncertainty Shocks are Aggregate Demand Shocks
}

\author{
Sylvain Leduc \\ Federal Reserve Bank of San Francisco \\ Zheng Liu \\ Federal Reserve Bank of San Francisco
}

May 2015

Working Paper 2012-10

http://www.frbsf.org/publications/economics/papers/2012/wp12-10bk.pdf

\section{Suggested citation:}

Leduc, Sylvain and Zheng Liu. 2015. "Uncertainty Shocks are Aggregate Demand Shocks.” Federal Reserve Bank of San Francisco Working Paper 2012-10. http://www.frbsf.org/economic-research/publications/working-papers/wp12-10bk.pdf

The views in this paper are solely the responsibility of the authors and should not be interpreted as reflecting the views of the Federal Reserve Bank of San Francisco or the Board of Governors of the Federal Reserve System. 


\title{
UNCERTAINTY SHOCKS ARE AGGREGATE DEMAND SHOCKS
}

\author{
SYLVAIN LEDUC AND ZHENG LIU
}

\begin{abstract}
We show that to capture the empirical effects of uncertainty on the unemployment rate, it is crucial to study the interactions between search frictions and nominal rigidities. Our argument is guided by empirical evidence showing that an increase in uncertainty leads to a large increase in unemployment and a significant decline in inflation, suggesting that uncertainty partly operates via an aggregate demand channel. To understand the mechanism through which uncertainty generates these macroeconomic effects, we incorporate search frictions and nominal rigidities in a DSGE model. We show that an option-value channel that arises from search frictions interacts with a demand channel that arises from nominal rigidities, and such interactions magnify the effects of uncertainty to generate roughly 60 percent of the observed increase in unemployment following an uncertainty shock.
\end{abstract}

\section{INTRODUCTION}

Measures of uncertainty surged in the Great Recession of 2008-2009 and remained elevated during most of the recovery period. Some have argued that increases in uncertainty contributed to the deep recession and the slow recovery, with a persistently high unemployment rate. In this paper, we present a DSGE framework with search frictions and nominal rigidities to illustrate a new transmission mechanism through which uncertainty can produce large macroeconomic effects. This mechanism works through an interaction between

Date: May 11, 2015.

Key words and phrases. Uncertainty, aggregate demand, labor search frictions, option-value channel, unemployment, inflation, survey data.

JEL classification: E21, E27, E32.

Leduc: Federal Reserve Bank of San Francisco; Email: Sylvain.Leduc@sf.frb.org. Liu: Federal Reserve Bank of San Francisco; Email: Zheng.Liu@sf.frb.org. We thank the editors Ricardo Reis and Nir Jaimovich and an anonymous referee for critical comments that have helped improve the quality of the paper. We also thank Susanto Basu, Nick Bloom, Toni Braun, Larry Christiano, Mary Daly, John Fernald, Jesús FernándezVillaverde, Simon Gilchrist, Federico Ravenna, Juan F. Rubio-Ramírez, John Williams, Tao Zha and seminar participants at the Federal Reserve Banks of Atlanta and San Francisco, the Bank of Canada, the Canadian Macro Study Group, the 2012 NBER Productivity and Macroeconomics meeting, the 2012 NBER Workshop on Methods and Applications for Dynamic Stochastic General Equilibrium Models, the 2013 SED meeting in Seoul, and the 2013 Summer Workshop of the Stanford Institute for Theoretical Economics. We are especially grateful to Tao Zha for providing us with his computer code for estimating Bayesian VAR models. The views expressed herein are those of the authors and do not necessarily reflect the views of the Federal Reserve Bank of San Francisco or the Federal Reserve System. 
an option-value channel that arises from labor search frictions and an aggregate-demand channel associated with nominal rigidities.

Our theoretical framework is guided by empirical evidence about the joint dynamics of unemployment and inflation following an uncertainty shock. We show that, in a small-scale Bayesian vector-autoregression (BVAR) model, an increase in uncertainty raises unemployment and lowers inflation, suggesting that the macroeconomic effects of uncertainty operate partly through an aggregate-demand channel. This empirical pattern is robust to the use of alternative measures of uncertainty, including standard measures such as the CBOE Volatility Index (VIX) and a novel measure of consumers' perceived uncertainty constructed using data from the Thomson Reuters/University of Michigan Surveys of Consumers. Despite the weak correlation between the raw time series of the VIX and consumer uncertainty measure, the BVAR model consistently predicts that uncertainty shocks act like a negative aggregate demand shock, raising unemployment and lowering inflation, independent of the particular measure of uncertainty used. Furthermore, the BVAR evidence suggests that uncertainty shocks lead to large increases in the unemployment rate. The large real effect of uncertainty shocks presents a challenge for standard DSGE models (e.g., Born and Pfeifer (2014)).

We use our theoretical framework to examine the mechanism through which uncertainty shocks can generate the large increase in unemployment and the fall in inflation observed empirically. Consistent with our VAR evidence, the DSGE model predicts that a rise in uncertainty raises the unemployment rate and lowers the inflation rate. More importantly, our model suggests that the interactions between search frictions and nominal rigidities are the key to obtaining the observed large increase in unemployment following an uncertainty shock.

I.1. The key mechanism. First, nominal rigidities help amplify the effect of uncertainty shocks on the unemployment rate through declines in aggregate demand, as in the standard DSGE model without search frictions (Fernández-Villaverde et al., 2013; Basu and Bundick, 2011). In our model with search frictions, the decline in aggregate demand reduces the value of a new match so that firms post fewer job vacancies, pushing the unemployment rate up. As more searching workers fail to find a job match, household incomes decline further. This leads to an even greater fall in aggregate demand, which magnifies the effects of uncertainty shocks. In addition, with sticky prices, inflation falls as aggregate demand declines, in line with our evidence.

Second, search frictions provide an additional mechanism for uncertainty shocks to generate large increases in unemployment via an option-value channel. With search frictions, a job match represents a long-term employment relationship that is irreversible. When times are uncertain, the option value of waiting increases and the match value declines. Firms 
respond by reducing hiring. This option-value effect in our model with search frictions arises for a similar reason as in the literature of irreversible investment decisions under uncertainty (Bernanke, 1983; Bloom, 2009; Bloom et al., 2012).

Indeed, in our model with search frictions, uncertainty shocks can be contractionary even with flexible prices, in contrast to the real business cycles (RBC) model with a spot labor market. A contraction occurs as long as the option-value channel dominates the effect of precautionary savings, which lowers interest rates and boosts the present value of a job match. When prices are sticky, an increase in uncertainty also leads to a decline in aggregate demand (the demand channel), which reinforces the option-value channel and generates an increase in unemployment that is roughly 60 percent of that observed in the data. Search frictions also amplify the decline in inflation, although the magnitude of the fall in prices remains notably smaller than what we see in the data.

We then examine the relative importance of these two channels through the lens of our model. Absent significant search frictions, the demand channel alone accounts for at most 16 percent of the observed increase in the unemployment rate following an uncertainty shock. This relatively small impact of uncertainty on real economic activity is in line with the recent findings of Born and Pfeifer (2014) using a standard DSGE model without search frictions. Similarly, absent nominal rigidities, the option-value channel alone accounts for a small fraction of the observed increase in the unemployment rate following an uncertainty shock. This finding is consistent with Schaal (2012), who studies a search model with flexible prices. He obtains sizable effects from idiosyncratic volatility shocks - his measure of uncertaintybut partly by assuming that these volatility shocks are negatively correlated with the level of aggregate productivity. Instead, when the option-value channel and the demand channel are simultaneously operating, as in our model, they interact to amplify the effects of uncertainty shocks and generate unemployment responses that are broadly in line with the data.

I.2. Relation to the literature. Our work adds to the recent burgeoning literature on the macroeconomic effects of uncertainty. On the empirical side, we document a new stylized fact that uncertainty acts like a decline in aggregate demand that raises unemployment and lower inflation. We show that this result holds when we use the standard VIX to measure uncertainty or when we use a new measure of consumers' perceived uncertainty constructed from survey data. Our empirical approach thus complements those in the literature, where uncertainty is measured using cross-sectional dispersions of earnings or productivity at the firm or industry levels (Bloom, 2009; Bloom et al., 2012), the conditional variance of the unforecastable component in statistical models (Jurado et al., 2013; Scotti, 2012), forecast disagreements (Bloom, 2009; Bachmann et al., 2013), or the volatility of fiscal instruments estimated under time-varying volatilities (Fernández-Villaverde et al., 2013). 
On the theory side, we show that an uncertainty shock can generate the observed demandlike macroeconomic effects through interactions between an option-value channel stemming from search frictions and an aggregate demand channel associated with nominal rigidities. Our model complements the recent theoretical literature on the macroeconomic effects of uncertainty. This strand of literature is too vast to enumerate. ${ }^{1}$ However, to our knowledge, our emphasis on the interactions between the option-value channel and the aggregate-demand channel for the transmission of uncertainty shocks is new to the literature.

\section{UNCERTAINTY, UNEMPLOYMENT AND INFLATION: EMPIRICAL EVIDENCE}

In this section, we examine the macroeconomic effects of uncertainty shocks in the data. We consider two alternative measures of uncertainty: The VIX commonly used in the literature (Bloom, 2009), and a new measure of consumers' perceived uncertainty (or consumer uncertainty) constructed from the Thomson Reuters/University of Michigan Surveys of Consumers. We show that, although the time series behaviors of these two measures of uncertainty are quite different, the macroeconomic effects of uncertainty shocks based on the two different measures are remarkably similar.

II.1. The measures of uncertainty. Our new measure of uncertainty is constructed based on the Michigan Survey. Since January 1978, the Michigan Survey has conducted monthly interviews of about 500 households throughout the United States. One survey question asks: "Speaking now of the automobile market-do you think the next 12 months or so will be a good time or a bad time to buy a vehicle, such as a car, pickup, van or sport utility vehicle?" A follow-up question asks: "Why do you say so?" The survey tallies the fraction of respondents who report that "uncertain future" is a reason why it will be a bad time to buy cars or other durable goods over the next 12 months. The series is weighted by age, income, region, and sex and is nationally representative.

Figure 1 shows the time-series plots of consumers' perceived uncertainty (concerning vehicle purchases) along with the VIX. ${ }^{2}$ The main similarity between the two measures of uncertainty is that they are both countercyclical. They rise in recessions and fall in expansions. However, the two series appear otherwise very different. One notable difference is in 1997-98. The VIX surged following the East Asian financial crisis and the Russian debt crisis, but consumer uncertainty remained at historically low levels. Another notable

\footnotetext{
${ }^{1}$ A partial list includes Bloom (2009), Gilchrist et al. (2010), Arellano et al. (2011), Basu and Bundick (2011), Ilut and Schneider (2011), Fernández-Villaverde et al. (2013), Bloom et al. (2012), Gourio (2012), Bidder and Smith (2012), and Born and Pfeifer (2014). See Bloom (2014) for a survey.

${ }^{2}$ The VIX constructed by the Chicago Board of Exchange (CBOE) starts in January 1990. We extend the series back to January 1986 by using the CBOE's VXO for the pre-1990 period.
} 
difference is in late 2012, when the U.S. economy faced the possibility of a "fiscal cliff" that could potentially trigger large tax increases and government spending cuts if Congress and the White House failed to reach an agreement about deficit reductions. In that period, consumer uncertainty remained elevated but the VIX was very low. ${ }^{3}$ Anecdotal evidence aside, the two measures of uncertainty are only weakly correlated, with a sample correlation of about 0.24 during the period from January 1986 (the beginning of the VIX/VXO series) and October 2013.

II.2. VAR evidence. Despite the apparent differences in the raw time series of our consumer uncertainty measure and the VIX, we find that the macroeconomic effects of uncertainty shocks in an estimated BVAR model are remarkably similar across the two measures of uncertainty.

The baseline BVAR model contains four time-series variables: a measure of uncertainty (consumer uncertainty or VIX), the unemployment rate, the inflation rate measured as yearover-year changes in the consumer price index (CPI), and the three-month Treasury bills rate. When we use the consumer uncertainty measure, the sample covers the period from January 1978 to October 2013. When we use the VIX, the sample ranges from January 1986 to October 2013. We adopt a flat prior for estimating the BVAR model. ${ }^{4}$

An advantage of our consumer uncertainty measure relative to the VIX is that we are able to exploit the timing of the survey interviews relative to the timing of macroeconomic data releases to identify the uncertainty shock. In the Michigan survey, telephone interviews are conducted throughout the month, with most interviews concentrated in the middle of each month, and preliminary results released shortly thereafter. The final results are typically released by the end of the month. When answering questions, survey participants have information about the previous month's unemployment, inflation, and interest rates, but they do not have (complete) information about the current-month macroeconomic conditions because the macroeconomic data have not yet been made public. Hence, our identification strategy uses the fact that, when answering questions at time $t$ about their expectations of the future, the information set on which survey participants condition their answers will not include, by construction, the time $t$ realizations of the unemployment rate and the other variables in our BVAR model.

Thus, we place the consumer uncertainty measure as the first variable in the BVAR model. This Cholesky ordering implies that uncertainty does not respond to macroeconomic shocks

\footnotetext{
${ }^{3} \mathrm{~A}$ possible explanation is that the VIX focuses on short-term uncertainty because it is a weighted average of 30-day-ahead option prices.

${ }^{4}$ Our results are robust to using Bayesian priors proposed by Sims and Zha (1998), which may help improve the estimation of error bands in short time-series samples of data.
} 
in the impact period, but unemployment, inflation, and the nominal interest rate are allowed to respond to an uncertainty shock. In subsequent periods, however, uncertainty responds to all shocks through its relation to the lags of the macroeconomic variables as specified in the BVAR model. Our Cholesky identification strategy here is similar to that in Leduc et al. (2007), Auerbach and Gorodnichenko (2012), and Leduc and Sill (forthcoming). ${ }^{5}$

Figure 2 presents the impulse responses in the BVAR model, in which consumer uncertainty is ordered first. For each variable, the solid line denotes the median estimate of the impulse response and the dashed lines represent the range of the 90-percent confidence band around the point estimates. The figure shows that an unexpected increase in uncertainty leads to a persistent increase in the unemployment rate. The increase in unemployment remains significant at the 90-percent level for about three years, with the peak effect occurring about 18 months from the impact period.

Heightened uncertainty also leads to a persistent decline in the inflation rate, with the peak effect occurring roughly 20 months from the impact period. The decline in inflation becomes significant at the 90-percent level in about eight months and remains significant for about two years. The rise in unemployment and the fall in inflation suggest that uncertainty operates through an aggregate demand channel that reduces both economic activity and prices.

Although the timing of the survey relative to macroeconomic data releases suggests that survey respondents do not possess complete information about the current-month macroeconomic data at the time of the interviews (which forms the basis of our Cholesky identification assumption in the benchmark BVAR model), they may observe other, possibly higher-frequency indicators that provide information about the time $t$ realizations of the variables in the BVAR model. To examine the sensitivity of our results to the Cholesky ordering of variables, we estimate a BVAR model with consumer uncertainty ordered last. This relatively conservative identification assumption implies that the measure of uncertainty is allowed to respond to all contemporaneous macroeconomic shocks.

Figure 3 presents the impulse responses in the BVAR model with this alternative ordering. The responses of the three macroeconomic variables to an uncertainty shock look remarkably similar to those in the benchmark BVAR with uncertainty ordered first. Under each identification strategy, a positive uncertainty shock acts like a negative aggregate demand shock that leads to persistent increases in unemployment and persistent declines in inflation,

\footnotetext{
${ }^{5}$ Bachmann and Moscarini (2011) argue that bad first-moment shocks can raise cross-sectional dispersions and time-series volatility of macroeconomic variables. In this sense, changes in measured uncertainty could reflect endogenous responses of macroeconomic variables to first-moment shocks. Our empirical approach allows measured uncertainty to react to macroeconomic shocks, but it also presumes that measured uncertainty contains some exogenous component.
} 
and the responses of both macroeconomic variables are statistically significant at the 90percent level. Under each identification, monetary policy reacts to the recessionary effects of uncertainty by lowering the nominal interest rate.

The aggregate demand effects of uncertainty are not an artifact of our measure of consumer uncertainty. They are also present when we replace the consumer uncertainty measure with the VIX, as Figure 4 shows. In particular, following a shock to uncertainty (measured by the VIX index), unemployment rises significantly for about two years, inflation declines significantly for about 15 months, and monetary policy accommodates by lowering the nominal interest rate.

II.3. Robustness of VAR evidence. We now show that the aggregate demand effects of uncertainty are robust when we replace the short-term nominal interest rate with a longterm interest rate to capture potential effects of unconventional monetary policy when the short-term rates are constrained by the zero lower bound. We also show that the aggregate demand effects of uncertainty do not reflect the responses of macroeconomic variables to changes in consumer confidence. We focus on the survey-based measure of uncertainty. The results are similar when we use the VIX instead. ${ }^{6}$

II.3.1. Monetary policy and the zero lower bound. Our sample covers the post-2008 period, during which U.S. monetary policy has been constrained by the zero lower bound (ZLB) on the short-term nominal interest rate. The inability of monetary policy to accommodate the negative effects of uncertainty when the ZLB is binding implies that our BVAR model could be misspecified. In reality, however, the Fed used unconventional monetary tools after the short-term nominal interest rate reached the zero lower bound. In particular, the Fed has conducted three rounds of large-scale asset purchases and provided systematic forward guidance about the future path of monetary policy.

To examine the importance of this issue for our results, we estimate a BVAR model with an alternative indicator of monetary policy. In particular, we use the two-year Treasury bond yields as an indicator of monetary policy instead of the three-month Treasury bills rate. ${ }^{7}$ Unlike the three-month Treasury bills rate, the two-year Treasury yields did not reach the zero lower bound. More importantly, the use of this longer-term interest rate helps capture the effects of unconventional monetary policy, which is designed to lower yields on

\footnotetext{
${ }^{6}$ To conserve space, we relegate these empirical results to an online appendix available at http://www.frbsf.org/economic-research/publications/working-papers/2012/ wp12-10bk_appendix.pdf.

${ }^{7}$ Swanson and Williams (2014) argue that the Federal Reserve's forward guidance policy typically attempts to influence the two-year Treasury bond yields. Gertler and Karadi (2013) also argue for the use of a longterm interest rate as an indicator of monetary policy in a VAR.
} 
long-term securities. Thus, we examine a BVAR model that is identical to the baseline fourvariable BVAR model, except that the short-term nominal interest rate series is replaced by a long-term interest rate series.

As in our baseline model, we find that a shock that raises uncertainty also raises the unemployment rate and lowers both the inflation rate and the two-year Treasury yields. These effects are persistent and statistically significant at the 90-percent level.

II.3.2. Uncertain future or bad economic times? As shown in Figure 1, consumer uncertainty rises in recessions and falls in booms. A priori, it is possible that consumer uncertainty from the Michigan Survey may reflect the respondents' perceptions of bad economic times rather than an uncertain future.

To assess the extent to which consumer uncertainty might reflect their perceptions of bad economic times, we examine how much the macroeconomic effects of shocks to consumer uncertainty reflect the responses to changes in other indicators of economic conditions, such as consumer confidence. For this purpose, we follow an approach similar to Baker et al. (2011) and estimate a five-variable BVAR model that includes a consumer sentiment index as an additional variable to control for potential effects from movements in consumer confidence.

We find that the macroeconomic effects of uncertainty shocks are qualitatively similar to those estimated from the benchmark BVAR. A shock to uncertainty raises the unemployment rate and lowers consumer sentiment, the inflation rate, and the short-term nominal interest rate. The responses of the macroeconomic variables are statistically significant at the 90 percent level. The results are similar when we replace the consumer sentiment for current economic conditions with that for future expectations. Thus, the macroeconomic effects of uncertainty shocks do not seem to reflect responses of macroeconomic variables to changes in consumer confidence.

\section{UNCERTAINTY SHOCKS IN A DSGE MODEL WITH SEARCH FRICTIONS}

In this section, we examine the channels that transmit uncertainty shocks to the macroeconomy in a DSGE model with sticky prices and labor market search frictions. We show that uncertainty shocks in the DSGE model act like an aggregate demand shock that raises unemployment, lowers inflation, and, through the Taylor rule, lowers the nominal interest rate, just as we have seen in the data. We further show that search frictions in the labor market and sticky prices in the goods market are both important for amplifying the effects of uncertainty shocks in the model.

The economy is populated by a continuum of infinitely lived and identical households with a unit measure. The representative household consists of a continuum of worker members. The household owns a continuum of firms, each of which uses one worker to produce an 
intermediate good. In each period, a fraction of the workers are unemployed and they search for jobs. Firms post vacancies at a fixed cost. The number of successful matches are produced with a matching technology that transforms searching workers and vacancies into an employment relation. Real wages are determined by Nash bargaining between a searching worker and a hiring firm.

The household consumes a basket of differentiated retail goods, each of which is transformed from the homogeneous intermediate good using a constant-returns technology. Retailers face a perfectly competitive input market (where they purchase the intermediate good) and a monopolistically competitive product market. Each retailer sets a price for its differentiated product, with price adjustments subject to a quadratic cost in the spirit of Rotemberg (1982).

The government finances its spending and transfer payments to unemployed workers by distortionary taxes on firm profits. Monetary policy is described by the Taylor rule, under which the nominal interest rate responds to deviations of inflation from a target and of output from its potential.

III.1. The households. There is a continuum of infinitely lived and identical households with a unit measure. The representative household consumes a basket of retail goods. The utility function is given by

$$
E \sum_{t=0}^{\infty} \beta^{t}\left[\ln \left(C_{t}-h C_{t-1}\right)-\chi N_{t}\right]
$$

where $E[\cdot]$ is an expectation operator, $C_{t}$ denotes consumption, and $N_{t}$ denotes the fraction of household members who are employed. The parameter $\beta \in(0,1)$ denotes the subjective discount factor, $h$ measures habit persistence, and $\chi$ captures the disutility from working.

The household chooses consumption $C_{t}$ and saving $B_{t}$ to maximize the utility function in (1) subject to the sequence of budget constraints

$$
C_{t}+\frac{B_{t}}{P_{t} R_{t}}=\frac{B_{t-1}}{P_{t}}+w_{t} N_{t}+\phi\left(1-N_{t}\right)+d_{t}-T_{t}, \quad \forall t \geq 0,
$$

where $P_{t}$ denotes the price level, $B_{t}$ denotes holdings of a nominal risk-free bond, $R_{t}$ denotes the nominal interest rate, $w_{t}$ denotes the real wage rate, $\phi$ denotes an unemployment benefit, $d_{t}$ denotes profit income from ownership of intermediate goods producers and of retailers, and $T_{t}$ denotes a lump-sum tax paid to the government.

Optimal bond-holding decisions are described by the intertemporal Euler equation

$$
1=\mathrm{E}_{t} \beta \frac{\Lambda_{t+1}}{\Lambda_{t}} \frac{R_{t}}{\pi_{t+1}}
$$


where $\pi_{t} \equiv \frac{P_{t}}{P_{t-1}}$ denotes the inflation rate, and $\Lambda_{t}$ denotes the marginal utility of consumption given by

$$
\Lambda_{t}=\frac{1}{C_{t}-h C_{t-1}}-\mathrm{E}_{t} \frac{\beta h}{C_{t+1}-h C_{t}} .
$$

III.2. The aggregation sector. Denote by $Y_{t}$ the final consumption good, which is a basket of differentiated retail goods. Denote by $Y_{t}(j)$ a type $j$ retail good for $j \in[0,1]$. We assume that

$$
Y_{t}=\left(\int_{0}^{1} Y_{t}(j)^{\frac{\eta-1}{\eta}}\right)^{\frac{\eta}{\eta-1}}
$$

where $\eta>1$ is the elasticity of substitution between differentiated products.

Expenditure minimizing implies that demand for a type $j$ retail good is inversely related to the relative price, with the demand schedule given by

$$
Y_{t}^{d}(j)=\left(\frac{P_{t}(j)}{P_{t}}\right)^{-\eta} Y_{t},
$$

where $Y_{t}^{d}(j)$ and $P_{t}(j)$ denote the demand for and the price of a retail good of type $j$, respectively. Zero-profit in the aggregate sector implies that the price index $P_{t}$ is related to the individual prices $P_{t}(j)$ through the relation

$$
P_{t}=\left(\int_{0}^{1} P_{t}(j)^{\frac{1}{1-\eta}}\right)^{1-\eta} .
$$

III.3. The retail goods producers. There is a continuum of retailers, each producing a differentiated product using a homogeneous intermediate good as input. The production function of a retail good of type $j \in[0,1]$ is given by

$$
Y_{t}(j)=X_{t}(j)
$$

where $X_{t}(j)$ is the input of intermediate goods used by retailer $j$ and $Y_{t}(j)$ is the output. The retail goods producers are price takers in the input market and monopolistic competitors in the product markets, where they set prices for their products, taking as given the demand schedule in equation (6) and the price index in equation (7).

Price adjustments are subject to the quadratic cost

$$
\frac{\Omega_{p}}{2}\left(\frac{P_{t}(j)}{\pi P_{t-1}(j)}-1\right)^{2} Y_{t}
$$

where the parameter $\Omega_{p} \geq 0$ measures the cost of price adjustments and $\pi$ denotes the steady-state inflation rate. Price adjustment costs are in units of aggregate output.

A retail firm that produces good $j$ solves the profit-maximizing problem

$$
\max _{P_{t}(j)} \quad \mathrm{E}_{t} \sum_{i=0}^{\infty} \frac{\beta^{i} \Lambda_{t+i}}{\Lambda_{t}}\left[\left(\frac{P_{t+i}(j)}{P_{t+i}}-q_{t+i}\right) Y_{t+i}^{d}(j)-\frac{\Omega_{p}}{2}\left(\frac{P_{t+i}(j)}{\pi P_{t+i-1}(j)}-1\right)^{2} Y_{t+i}\right] \text {, }
$$


where $q_{t}$ denotes the relative price of intermediate goods. The optimal price-setting decision implies that, in a symmetric equilibrium with $P_{t}(j)=P_{t}$ for all $j$, we have

$$
q_{t}=\frac{\eta-1}{\eta}+\frac{\Omega_{p}}{\eta}\left[\frac{\pi_{t}}{\pi}\left(\frac{\pi_{t}}{\pi}-1\right)-\mathrm{E}_{t} \frac{\beta \Lambda_{t+1}}{\Lambda_{t}} \frac{Y_{t+1}}{Y_{t}} \frac{\pi_{t+1}}{\pi}\left(\frac{\pi_{t+1}}{\pi}-1\right)\right] .
$$

Absent price adjustment costs (i.e., $\Omega_{p}=0$ ), the optimal pricing rule implies that real marginal cost $q_{t}$ equals the inverse of the steady-state markup.

III.4. The Labor Market. In the beginning of period $t$, there are $u_{t}$ unemployed workers searching for jobs and there are $v_{t}$ vacancies posted by firms. The matching technology is described by the Cobb-Douglas function

$$
m_{t}=\mu u_{t}^{\alpha} v_{t}^{1-\alpha},
$$

where $m_{t}$ denotes the number of successful matches and the parameter $\alpha \in(0,1)$ denotes the elasticity of job matches with respect to the number of searching workers. The parameter $\mu$ scales the matching efficiency.

The probability that an open vacancy is matched with a searching worker (i.e., the job filling rate) is given by

$$
q_{t}^{v}=\frac{m_{t}}{v_{t}} .
$$

The probability that an unemployed and searching worker is matched with an open vacancy (i.e., the job finding rate) is given by

$$
q_{t}^{u}=\frac{m_{t}}{u_{t}} .
$$

In the beginning of period $t$, there are $N_{t-1}$ workers. A fraction $\rho$ of these workers lose their jobs. Thus, the number of workers who survive the job separation is $(1-\rho) N_{t-1}$. At the same time, $m_{t}$ new matches are formed. Following the timing assumption in Blanchard and Galí (2010), we assume that new hires start working in the period they are hired. Thus, aggregate employment in period $t$ evolves according to

$$
N_{t}=(1-\rho) N_{t-1}+m_{t} .
$$

With a fraction $\rho$ of employed workers separated from their jobs, the number of unemployed workers searching for jobs in period $t$ is given by

$$
u_{t}=1-(1-\rho) N_{t-1} .
$$

Following Blanchard and Galí (2010), we assume full participation and define the unemployment rate as the fraction of the population who are left without a job after hiring takes place in period $t$. Thus, the unemployment rate is given by

$$
U_{t}=u_{t}-m_{t}=1-N_{t} .
$$


III.5. The firms (intermediate good producers). A firm can produce only if it successfully hires a worker. The production function for a firm with one worker is given by

$$
x_{t}=Z_{t},
$$

where $x_{t}$ denotes output. The term $Z_{t}$ denotes an aggregate technology shock, which follows the stationary stochastic process

$$
\ln Z_{t}=\rho_{z} \ln Z_{t-1}+\sigma_{z t} \varepsilon_{z t}
$$

The parameter $\rho_{z} \in(-1,1)$ measures the persistence of the technology shock. The term $\varepsilon_{z t}$ is an i.i.d. innovation to the technology shock and is a standard normal process. The term $\sigma_{z t}$ is a time-varying standard deviation of the innovation, which we interpret as a technology uncertainty shock. We assume that the uncertainty shock follows the stationary stochastic process

$$
\ln \sigma_{z t}=\left(1-\rho_{\sigma_{z}}\right) \ln \sigma_{z}+\rho_{\sigma_{z}} \ln \sigma_{z, t-1}+\sigma_{\sigma_{z}} \varepsilon_{\sigma_{z}, t}
$$

where the parameter $\rho_{\sigma_{z}} \in(-1,1)$ measures the persistence of the uncertainty shock, the term $\varepsilon_{\sigma_{z}, t}$ is an i.i.d. standard normal process, and the parameter $\sigma_{\sigma_{z}}>0$ is the standard deviation of the innovation to technology uncertainty.

If a firm finds a match, it obtains a flow profit in the current period after paying the worker. In the next period, if the match survives (with probability $1-\rho$ ), the firm continues; if the match breaks down (with probability $\rho$ ), the firm posts a new job vacancy at a fixed cost $\kappa$, with the value $V_{t+1}$. The value of a firm with a match (denoted by $J_{t}^{F}$ ) is therefore given by the Bellman equation

$$
J_{t}^{F}=q_{t} Z_{t}-w_{t}+E_{t} \frac{\beta \Lambda_{t+1}}{\Lambda_{t}}\left[(1-\rho) J_{t+1}^{F}+\rho V_{t+1}\right] .
$$

If the firm posts a new vacancy in period $t$, it costs $\kappa$ units of final goods. The vacancy can be filled with probability $q_{t}^{v}$, in which case the firm obtains the value of the match. Otherwise, the vacancy remains unfilled and the firm goes into the next period with the value $V_{t+1}$. Thus, the value of an open vacancy is given by

$$
V_{t}=-\kappa+q_{t}^{v} J_{t}^{F}+E_{t} \frac{\beta \Lambda_{t+1}}{\Lambda_{t}}\left(1-q_{t}^{v}\right) V_{t+1}
$$

Free entry implies that $V_{t}=0$, so that

$$
\frac{\kappa}{q_{t}^{v}}=J_{t}^{F}
$$

This relation describes the optimal job creation decisions. The benefit of creating a new job is the match value $J_{t}^{F}$. The expected cost of creating a new job is the flow cost of posting a vacancy $\kappa$ multiplied by the expected duration of an unfilled vacancy $1 / q_{t}^{v}$. 
III.6. Workers' value functions. If a worker is employed, he obtains wage income but suffers a utility cost of working. In period $t+1$, the match is separated with probability $\rho$ and the separated worker can find a new match with probability $q_{t+1}^{u}$. Thus, with probability $\rho(1-$ $\left.q_{t+1}^{u}\right)$, a separated worker fails to find a new job in period $t+1$ and enters the unemployment pool. Otherwise, the worker continues to be employed. The (marginal) value of an employed worker (denoted by $J_{t}^{W}$ ) therefore satisfies the Bellman equation

$$
J_{t}^{W}=w_{t}-\frac{\chi}{\Lambda_{t}}+E_{t} \frac{\beta \Lambda_{t+1}}{\Lambda_{t}}\left\{\left[1-\rho\left(1-q_{t+1}^{u}\right)\right] J_{t+1}^{W}+\rho\left(1-q_{t+1}^{u}\right) J_{t+1}^{U}\right\},
$$

where $J_{t}^{U}$ denotes the value of an unemployed worker. An unemployed worker obtains the flow unemployment benefit $\phi$ and can find a new job in period $t+1$ with probability $q_{t+1}^{u}$. Thus, the value of an unemployed worker satisfies the Bellman equation

$$
J_{t}^{U}=\phi+E_{t} \frac{\beta \Lambda_{t+1}}{\Lambda_{t}}\left[q_{t+1}^{u} J_{t+1}^{W}+\left(1-q_{t+1}^{u}\right) J_{t+1}^{U}\right] .
$$

III.7. The Nash bargaining wage. Firms and workers bargain over wages. The Nash bargaining problem is given by

$$
\max _{w_{t}}\left(J_{t}^{W}-J_{t}^{U}\right)^{b}\left(J_{t}^{F}\right)^{1-b},
$$

where $b \in(0,1)$ represents the bargaining weight for workers.

Define the total surplus as

$$
S_{t}=J_{t}^{F}+J_{t}^{W}-J_{t}^{U}
$$

Then the bargaining solution is given by

$$
J_{t}^{F}=(1-b) S_{t}, \quad J_{t}^{W}-J_{t}^{U}=b S_{t} .
$$

It then follows from equations (22) and (23) that

$$
b S_{t}=w_{t}^{N}-\phi-\frac{\chi}{\Lambda_{t}}+E_{t} \frac{\beta \Lambda_{t+1}}{\Lambda_{t}}\left[(1-\rho)\left(1-q_{t+1}^{u}\right) b S_{t+1}\right] .
$$

Given the bargaining surplus $S_{t}$, which itself is proportional to the match value $J_{t}^{F}$, this last equation determines the Nash bargaining wage $w_{t}^{N}$.

If the equilibrium real wage equals the Nash bargaining wage, then we can obtain an explicit expression for the Nash bargaining wage. Specifically, we use equations (21), (26), and (27) and impose $w_{t}=w_{t}^{N}$ to obtain

$$
w_{t}^{N}=(1-b)\left[\frac{\chi}{\Lambda_{t}}+\phi\right]+b\left[q_{t} Z_{t}+\beta(1-\rho) E_{t} \frac{\beta \Lambda_{t+1}}{\Lambda_{t}} \frac{\kappa v_{t+1}}{u_{t+1}}\right]
$$

In this case, the Nash bargaining wage is a weighted average of the worker's reservation value and the firm's productive value of a job match. By forming a match, the worker incurs a utility cost of working and forgoes unemployment benefits. By employing a worker, the firm 
receives the marginal product from labor in the current period and saves the vacancy cost from the next period.

III.8. Wage Rigidity. In general, however, the equilibrium real wage may be different from the Nash bargaining solution. Hall (2005) points out that real wage rigidity is important to generate empirically reasonable volatilities of vacancies and unemployment.

There are several ways to formalize real wage rigidity (Hall, 2005; Hall and Milgrom, 2008; Gertler and Trigari, 2009; Blanchard and Galí, 2010). We follow the literature and assume that

$$
w_{t}=w_{t-1}^{\gamma}\left(w_{t}^{N}\right)^{1-\gamma},
$$

where $\gamma \in(0,1)$ represents the degree of real wage rigidity. ${ }^{8}$

III.9. Government policy. The government finances transfer payments for unemployment benefits through lumpsum taxes. We assume that the government balances the budget in each period so that

$$
\phi\left(1-N_{t}\right)=T_{t} .
$$

The monetary authority follows the Taylor rule

$$
R_{t}=r \pi^{*}\left(\frac{\pi_{t}}{\pi^{*}}\right)^{\phi_{\pi}}\left(\frac{Y_{t}}{Y}\right)^{\phi_{y}},
$$

where the parameter $\phi_{\pi}$ determines the aggressiveness of monetary policy against deviations of inflation from the target $\pi^{*}$ and $\phi_{y}$ determines the extent to which monetary policy accommodates output fluctuations. The parameter $r$ denotes the steady-state real interest rate (i.e., $r=\frac{R}{\pi}$ ).

III.10. Search equilibrium. In a search equilibrium, the markets for bonds, final consumption goods, and intermediate goods all clear.

Since the aggregate supply of the nominal bond is zero, the bond market-clearing condition implies that

$$
B_{t}=0
$$

Goods market clearing implies the aggregate resource constraint

$$
C_{t}+\kappa v_{t}+\frac{\Omega_{p}}{2}\left(\frac{\pi_{t}}{\pi}-1\right)^{2} Y_{t}=Y_{t},
$$

where $Y_{t}$ denotes aggregate output of final goods.

Intermediate goods market clearing implies that

$$
Y_{t}=Z_{t} N_{t} .
$$

\footnotetext{
${ }^{8}$ We have examined other wage rules such as those in Blanchard and Galí (2010) and we find that our results do not depend on the particular form of the wage rule.
} 


\section{ECONOMIC IMPLiCATIONS OF THE DSGE MODEL}

To examine the macroeconomic effects of uncertainty shocks in our DSGE model, we calibrate the model parameters and simulate the model to examine impulse responses of macroeconomic variables to the two alternative sources of uncertainty shocks. We focus on the responses of unemployment, inflation, and the nominal interest rate following an uncertainty shock.

IV.1. Calibration. We calibrate the structural parameters to match several steady-state observations. For those structural parameters that do not affect the model's steady state, we calibrate their values to be consistent with other empirical studies in the literature. The structural parameters to be calibrated include $\beta$, the subjective discount factor; $h$, the habit persistence parameter; $\chi$, the disutility of working parameter; $\eta$, the elasticity of substitution between differentiated retail products; $\alpha$, the elasticity of matching with respect to searching workers; $\mu$, the matching efficiency parameter; $\rho$, the job separation rate; $\phi$, the flow of unemployment benefits (in final consumption units); $\kappa$, the fixed cost of posting vacancies; $b$, the Nash bargaining weight; $\Omega_{p}$, the price adjustment cost parameter; $\pi$, the steady-state inflation rate (which is also the inflation target); $\phi_{\pi}$, the Taylor-rule coefficient for inflation; and $\phi_{y}$, the Taylor-rule coefficient for output. In addition, we need to calibrate the parameters in the shock processes. The calibrated values of the model parameters are summarized in Table 1.

We set $\beta=0.99$, so that the model implies a steady-state real interest rate of 4 percent per year. As a baseline for our analysis, we set $h=0$ so that there is no internal habit formation. When we study the role of habit persistence in amplifying uncertainty shocks relative to the baseline, we assume a value of $h=0.6$, in line with empirical studies such as Boldrin et al. (2001).

We calibrate the parameters related to labor search frictions based on existing studies. We set the matching elasticity parameter $\alpha$ to 0.5 and the wage bargaining parameter $b$ to 0.5 following Blanchard and Galí (2010). We calibrate the job separation rate $\rho$ to 0.1 , which is consistent with an average monthly job separation rate of about 3.5 percent observed in the Job Openings and Labor Turnover Survey (JOLTS). We follow Hall and Milgrom (2008) by setting $\phi$ to 0.25 , implying that the unemployment benefit is on average about 25 percent of wage earnings.

We choose the value of the vacancy cost parameter $\kappa$ so that, in the steady state, the total cost of posting vacancies is about 2 percent of gross output. To assign a value of $\kappa$ then requires knowledge of the steady-state number of vacancies $v$ and the steady-state level of output $Y$. We calibrate the value of $v$ such that the steady-state vacancy filling 
rate is $q^{v}=0.7$, as in den Haan et al. (2000). We target a steady-state unemployment rate of $U=0.064$, to be consistent with the average unemployment rate in our data. Given the steady-state value of the job separation rate $\rho=0.1$, we obtain $m=\rho N=0.0936$. Thus, we have $v=\frac{m}{q^{v}}=\frac{0.0936}{0.7}=0.134$. To obtain a value for $Y$, we use the aggregate production function that $Y=Z N$ and normalize the level of technology such that $Z=1$. This procedure yields a calibrated value of $\kappa=0.14$.

Given the steady-state values of $m, u$, and $v$, we use the matching function to obtain an average matching efficiency of $\mu=0.645$. To obtain a value for $\chi$, we solve the steady-state system so that $\chi$ is consistent with an unemployment rate of 6.4 percent. The process results in $\chi=0.547$. We set the real wage rigidity parameter to $\gamma=0.8$.

We also calibrate the parameters related to nominal rigidities following the literature. In particular, we set $\eta=10$ so that the average markup is about 11 percent, which lies in the range estimated by Basu and Fernald (1997). We set the price adjustment cost parameter to $\Omega_{p}=112$ so that, to a first-order approximation, the slope of the Phillips curve in our model corresponds to that implied by a Calvo model with a duration of price contracts of four quarters.

For the Taylor rule parameters, we set $\phi_{\pi}=1.5$ and $\phi_{y}=0.2$. We set $\pi=1.005$, so that the steady-state inflation rate is about 2 percent per year, corresponding to the Federal Reserve's inflation objective.

We calibrate the parameters in the first-moment technology shock following the RBC literature. In particular, we set the average standard deviation to $\sigma_{z}=0.01$ and the persistence parameter to $\rho_{z}=0.90$.

We calibrate the parameters in the second-moment shock based on our VAR evidence. As we have discussed in the empirical section, a one standard deviation shock to consumer uncertainty raises the measure of uncertainty by 1.36 units relative to the sample mean of 3.47. Thus, the shock is equivalent to a 39.2 percent increase in the level of uncertainty relative to its mean $(1.36 / 3.47=0.392)$. Since we calibrate the mean standard deviation in our model to 1 percent, we set the standard deviation of the uncertainty shock to $\sigma_{\sigma_{z}}=0.392$ in light of the VAR evidence.

Our VAR evidence also shows that the effects of the uncertainty shock on measured uncertainty gradually decline over time. Specifically, in a period of 12 months, consumer uncertainty falls gradually to about 34 percent of its peak. This observation suggests that, if the uncertainty shock is approximated by an AR(1) process - as we assume in the model - then the persistence parameter should be about 0.913 at monthly frequencies (i.e., $0.913^{12} \approx 0.34$ ). In our quarterly model, this implies a value of the persistence parameter of about $\rho_{\sigma_{z}}=0.76$ (i.e., $\left.0.913^{3}=0.76\right)$. 
IV.2. Macroeconomic effects of uncertainty shocks. To examine the dynamic effects of uncertainty shocks, which are second-moment shocks in our model, we solve the model using third-order approximations to the equilibrium conditions around the steady state. We then compute the impulse responses following an uncertainty shock. ${ }^{9}$ We show that interactions between an option-value channel associated with search frictions and an aggregate demand channel associated with nominal rigidities help amplify the macroeconomic effects of uncertainty.

IV.2.1. The option-value channel. To illustrate the option-value channel, we focus on a flexible-price version of the DSGE model, in which the aggregate demand channel is shut off. The dynamic effects of uncertainty on labor market variables in our model can be best understood by examining the responses of the match value $\left(J^{F}\right)$ to uncertainty shocks. As equation (20) shows, the match value depends on both the current-period profit and the continuation value of a job match, with the latter discounted by the real interest rate. Uncertainty creates a precautionary saving motive which, all else equal, reduces the real interest rate and raises employment, by raising the continuation value of a job match, and thus output. This expansionary effect of uncertainty is similar to that found in a standard RBC model (e.g., Gilchrist and Williams (2005) and Basu and Bundick (2011)).

However, unlike the RBC model with a spot labor market, our model with search frictions implies that a job match represents a long-term employment contract that is irreversible in our model. As in the model of irreversible investment studied by Bernanke (1983), uncertainty gives rise to a real option-value effect that is contractionary. Facing higher uncertainty, the option value of waiting increases and the expected value of a job match decreases, inducing firms to post fewer vacancies, making it harder for unemployed workers to find jobs, and ultimately raising the equilibrium unemployment rate.

To illustrate the opposing effects from the option-value channel and precautionary savings, we plot in Figure 5 the impulse responses of unemployment, consumption, the real interest rate, and the match value following an uncertainty shock in the flexible-price model. The figure shows that consumption and the real interest rate both decline following an increase in

\footnotetext{
${ }^{9}$ We follow the same procedure as Fernández-Villaverdes et al. (2011) to compute the impulse responses. In particular, we first simulate the model (with third-order approximations to the decision rules) for 2,096 periods, starting from the deterministic steady state and with all shocks hitting the economy. We discard the first 2,000 periods to avoid dependence on initial conditions. We use the remaining 96 periods to compute the ergodic mean of each variable. Starting from the ergodic means, we conduct two different simulations of 20 periods each, one with an uncertainty shock (i.e., a one-standard-deviation increase in uncertainty in the first period) and the other with no shocks. The impulse responses are then calculated as the percentage differences between these two simulations. In reporting the impulse responses, we annualize the units of the inflation rate and the nominal interest rate.
} 
uncertainty, indicating the presence of precautionary saving. However, with search frictions, the option-value channel prevails over the precautionary saving effects, leading to an overall recession with a lower match value and a higher unemployment rate. This option-value channel would be absent in the standard RBC model with a spot labor market. Thus, our results suggest that incorporating labor search frictions in the DSGE model helps explain the macroeconomic effects of uncertainty.

IV.2.2. The aggregate demand channel. We now examine the aggregate demand channel for the transmission of uncertainty shocks. For this purpose, we consider the benchmark model with both search frictions and nominal rigidities.

Figure 6 displays the impulse responses of several key macroeconomic variables to a technology uncertainty shock. As shown in the figure, heightened uncertainty raises the unemployment rate by reducing aggregate demand. As demand falls, the relative price of intermediate goods declines, reducing firms' profit and the value of a job match. Firms respond to the decline in the match value by posting fewer vacancies. With fewer vacancies available, the job finding rate for searching workers declines and the unemployment rate rises. As more workers are unemployed, household income falls, reinforcing the initial decline in aggregate demand and further amplifying the recessionary effects of uncertainty on macroeconomic activity.

Since uncertainty depresses aggregate demand, it also lowers inflation. Under the Taylor rule, the central bank lowers the nominal interest rate to alleviate the adverse effects of uncertainty. Nonetheless, equilibrium unemployment still rises and equilibrium inflation still falls following a rise in uncertainty. Thus, the theory's predictions are broadly in line with our empirical evidence that uncertainty shocks act like a negative aggregate demand shock.

The magnitude of the increase in unemployment following an uncertainty shock in the DSGE model is somewhat smaller than, but comparable to, that estimated in the VAR model. In particular, the VAR model implies that a one-standard-deviation increase in consumer uncertainty (shown in Figure 2) leads to a peak increase of unemployment of about 2.55 percent relative to the sample average (i.e., an increase in unemployment of 0.163 percentage points from a sample average of 6.4 percent). The DSGE model implies an increase of unemployment of about 1.60 percent relative to the ergodic mean, so that the DSGE model can generate about 63 percent of the observed increase in unemployment following an uncertainty shock $(1.60 / 2.55 \approx 0.63)$.

IV.2.3. Interactions between the option-value channel and the aggregate demand channel. In our model, search frictions and nominal rigidities have important interactions that amplify the macroeconomic effects of uncertainty shocks. This is illustrated in Figure 7, which 
displays the response of unemployment to a technology uncertainty shock in four different models: the benchmark model (the solid blue line), a model with nominal rigidities but with low search frictions (the dashed green line), a model with search frictions but with no nominal rigidities (the dotted magenta line), and a model with habit formation (the dashed and dotted red line). ${ }^{10}$

Figure 7 shows that the response of unemployment to uncertainty in the benchmark model is much larger than those in the model with flexible prices and in the model with low search frictions. In particular, the relatively small impact of uncertainty on real economic activity in the model with low search frictions is in line with the findings of Born and Pfeifer (2014) in a standard DSGE model without search frictions. ${ }^{11}$ This result suggests that the optionvalue channel associated with search frictions and the aggregate demand channel stemming from nominal rigidities are both important for amplifying uncertainty shocks.

The figure also shows that incorporating habit persistence helps further amplify the effects of uncertainty on unemployment. Habit formation increases the persistence of the negative effects of uncertainty and thus induces a greater decline in the present value of a job match. As a consequence, in the presence of habit formation, unemployment rises more sharply following the increase in uncertainty than in the benchmark model. In contrast, in a standard model without search frictions, habit formation dampens the effect of uncertainty on economic activity, since the consumption decline is more muted in this case (see, for instance, Born and Pfeifer (2014)). In our model, while more muted, the more persistent decline in consumption under habit formation also amplifies the effect of the option-value channel, resulting in a greater rise in the unemployment rate in response to an uncertainty shock. Firms refrain from hiring since the possibility of a bad hiring decision may have long-lasting negative consequences ex post.

Overall, incorporating habit formation brings the magnitude of the peak unemployment response much closer to that estimated from the VAR model (2.38 percent vs. 2.55 percent). These results are quantitatively similar even when we remove real wage rigidities (by setting $\gamma$ to 0 instead of 0.8), as shown in Figure 8.

\footnotetext{
${ }^{10}$ In the model with low search frictions, we set the vacancy cost parameter to $\kappa=0.01$ (instead of the benchmark calibration of 0.14 ) and the job separation rate to $\delta=0.9$ (instead of the benchmark calibration of 0.1). These parameters are chosen to approximate a model with frictionless (and spot) labor markets. In the model with no nominal rigidities, we set the price adjustment cost parameter to $\Omega_{p}=0$ and keep all the other parameters at their calibrated values. In the model with habit formation, we set the habit persistence parameter to $h=0.6$ and keep all the other parameters at the calibrated values.

${ }^{11}$ With low search frictions in our model, the magnitude of the output responses to a technology uncertainty shock (not reported) is comparable to that obtained by Born and Pfeifer (2014).
} 


\section{CONCLusion}

We study the macroeconomic effects of uncertainty shocks and find that uncertainty shocks act like aggregate demand shocks both in the data and in a DSGE model with search frictions and sticky prices.

Using novel measures of uncertainty from survey data and a VAR model, we document robust evidence that an uncertainty shock leads to a rise in unemployment and declines in inflation and the nominal interest rate. This result is robust to alternative measures of uncertainty, alternative identification strategies, and alternative model specifications.

Incorporating search frictions in a DSGE model is important for understanding the macroeconomic effects of uncertainty. We show that search frictions give rise to an option-value channel through which uncertainty can lead to a recession even in a flexible-price model. Incorporating nominal rigidities opens up an aggregate-demand channel that reinforces the option-value channel to generate quantitatively significant recessionary effects of uncertainty. When the model is further augmented with habit formation, the calibrated DSGE model generates an unemployment response to uncertainty with a size close to that estimated from the VAR model. Thus, interactions between search frictions and nominal rigidities are important for amplifying the macroeconomic effects of uncertainty shocks.

To highlight the aggregate demand effects of uncertainty shocks, we have focused on a stylized model that abstracts from some realistic and potentially important features of the actual economy. For example, the model does not have endogenous capital accumulation and is thus not designed to study the effects of uncertainty shocks on business investment. To the extent that investment adjustments are costly, a similar option-value channel for investment would operate so that increases in uncertainty would reduce investment expenditures. Thus, incorporating endogenous capital accumulation in our model with search frictions may have important implications for the quantitative magnitude of the responses of potential and equilibrium output. However, in light of several recent studies in the literature (Basu and Bundick, 2011; Fernández-Villaverde et al., 2013), incorporating capital accumulation in a DSGE model with nominal rigidities is unlikely to change the qualitative transmission mechanism of uncertainty shocks that we have identified in this paper. 


\section{REFERENCES}

Arellano, C., Y. Bai, And P. Kehoe (2011): "Financial Markets and Fluctuations in Uncertainty," Federal Reserve Bank of Minneapolis Research Department Staff Report.

Auerbach, A. J. And Y. Gorodnichenko (2012): "Measuring the Output Responses to Fiscal Policy," American Economic Journal: Economic Policy, 4, 1-27.

Bachmann, R., S. Elstner, And E. R. Sims (2013): "Uncertainty and Economic Activity: Evidence from Business Survey Data," American Economic Journal: Macroeconomics, $5,217-249$.

Bachmann, R. And G. Moscarini (2011): "Business Cycles and Endogenous Uncertainty," Yale University Working Paper.

Baker, S. R., N. Bloom, And S. J. Davis (2011): "Measuring Economic Policy Uncertainty," Stanford University Working Paper.

BAsu, S. AND B. Bundick (2011): "Uncertainty Shocks in a Model of Effective Demand," Boston College Working Paper.

Basu, S. And J. G. Fernald (1997): "Returns to Scale in U.S. Production: Estimates and Implications," Journal of Political Economy, 105, 249-283.

Bernanke, B. S. (1983): "Irreversibility, Uncertainty, and Cyclical Investment," Quarterly Journal of Economics, 98, 85-106.

Bidder, R. M. And M. E. Smith (2012): "Robust Animal Spirits," Journal of Monetary Economics, 59, 738-750.

Blanchard, O. J. And J. Galí (2010): "Labor Markets and Monetary Policy: A New Keynesian Model with Unemployment," American Economic Journal: Macroeconomics, $2,1-30$.

Bloom, N. (2009): "The Impact of Uncertainty Shocks," Econometrica, 77, 623-685.

- (2014): "Fluctuations in Uncertainty," Journal of Economic Perspectives, forthcoming.

Bloom, N., M. Floetotto, N. Jaimovich, I. Saporta-Eksten, and S. J. Terry (2012): "Really Uncertain Business Cycles," NBER Working Paper 18245.

Boldrin, M., L. J. Christiano, And J. D. Fisher (2001): "Habit Persistence, Asset Returns, and the Business Cycle," American Economic Review, 91, 149-166.

Born, B. And J. Pfeifer (2014): "Policy Risk and the Business Cycle," Journal of Monetary Economics, 68, 68-85.

den HaAn, W. J., G. Ramey, and J. Watson (2000): "Job Destruction and Propagation of Shocks," American Economic Review, 90, 482-498. 
Fernández-Villaverde, J., P. Guerrón-Quintana, K. Kuester, and J. RubioRAmírez (2013): "Fiscal Volatility Shocks and Economic Activity," University of Pennsylvania Working Paper.

Fernández-Villaverdes, J., P. Guerrón-Quintana, J. F. Rubio-Ramírez, and M. Uribe (2011): "Risk Matters: The Real Effects of Volatility Shocks," American Economic Review, 101, 2530-2561.

Gertler, M. and P. Karadi (2013): "Monetary Policy Surprises, Credit Costs and Economic Activity," Unpublished manuscript, New York University and the European Center Bank.

Gertler, M. And A. Trigari (2009): "Unemployment Fluctuations with Staggered Nash Wage Bargaining," Journal of Political Economy, 117.

Gilchrist, S., J. W. Sim, And E. Zakrajsek (2010): "Uncertainty, Financial Frictions, and Investment Dynamics," Boston University Working Paper.

Gilchrist, S. and J. C. Williams (2005): "Investment, Capacity, and Uncertainty: A Putty-Clay Approach," Review of Economic Dynamics, 8, 1-27.

Gourio, F. (2012): "Disaster Risk and Business Cycles," American Economic Review, 102, $2734-2766$.

Hall, R. E. (2005): "Employment Fluctuations with Equilibrium Wage Stickiness," American Economic Review, 95, 50-65.

Hall, R. E. And P. R. Milgrom (2008): "The Limited Influence of Unemployment on the Wage Bargain," American Economic Review, 98,

Ilut, C. L. And M. Schneider (2011): "Ambiguous Business Cycles," Working paper, Duke University and Stanford University.

Jurado, K., S. C. Ludvigson, And S. NG (2013): "Measuring Uncertainty," Unpublished manuscript, Columbia University and New York University.

Leduc, S. AND K. SiLl (forthcoming): "Expectations and Economic Fluctuations: An Analysis Using Survey Data," Review of Economics and Statistics.

Leduc, S., K. Sill, And T. Stark (2007): "Self-Fulfilling Expectations and the Inflation of the 1970s: Evidence from the Livingston Survey," Journal of Monetary Economics, 54, 433-459.

Rotemberg, J. J. (1982): "Sticky Prices in the United States," Journal of Political Economy, 90, 1187-1211.

SchaAl, E. (2012): "Uncertainty, Productivity and Unemployment in the Great Recession," Unpublished manuscript, Federal Reserve Bank of Minneapolis.

Scotтi, C. (2012): "Surprise and Uncertainty Indexes: Real-time Aggregation of RealActivity Macro Surprises," Unpublished manuscript, Federal Reserve Board. 
Sims, C. A. And T. Zha (1998): "Bayesian Methods for Dynamic Multivariate Models," International Economic Review, 39, 949-968.

Swanson, E. T. And J. C. Williams (2014): "Measuring the Effect of the Zero Lower Bound on Medium- and Longer-Term Interest Rates," American Economic Review (forthcoming). 
TABLE 1. Benchmark parameter calibration

\begin{tabular}{lll}
\hline \hline Parameter & Description & value \\
\hline$\beta$ & Structural parameters & \\
$\chi$ & Household's discount factor & 0.99 \\
$h$ & Scale of disutility of working & 0.547 \\
$\eta$ & Habit persistence & 0 \\
$\alpha$ & Elasticity of substitution between differentiated goods & 10 \\
$\mu$ & Share parameter in matching function & 0.50 \\
$\rho$ & Matching efficiency & 0.645 \\
$\phi$ & Job separation rate & 0.10 \\
$\kappa$ & Flow benefit of unemployment & 0.25 \\
$b$ & Flow cost of vacancy & 0.14 \\
$\gamma$ & Nash bargaining weight & 0.5 \\
$\Omega_{p}$ & Real wage rigidity & 0.8 \\
$\pi$ & Price adjustment cost & 112 \\
$\phi_{\pi}$ & Steady-state inflation (or inflation target) & 1.005 \\
$\phi_{y}$ & Taylor-rule coefficient for inflation & 1.5 \\
\hline & Taylor-rule coefficient for output & 0.2 \\
\hline$\rho_{z}$ & Shock parameters & \\
$\sigma_{z}$ & Persistence of technology level shock & 0.90 \\
$\rho_{\sigma_{z}}$ & Mean volatility of technology shock & 0.01 \\
$\sigma_{\sigma_{z}}$ & Persistence of technology uncertainty shock & 0.76 \\
\hline & Standard deviation of technology uncertainty shock & 0.392 \\
\hline
\end{tabular}




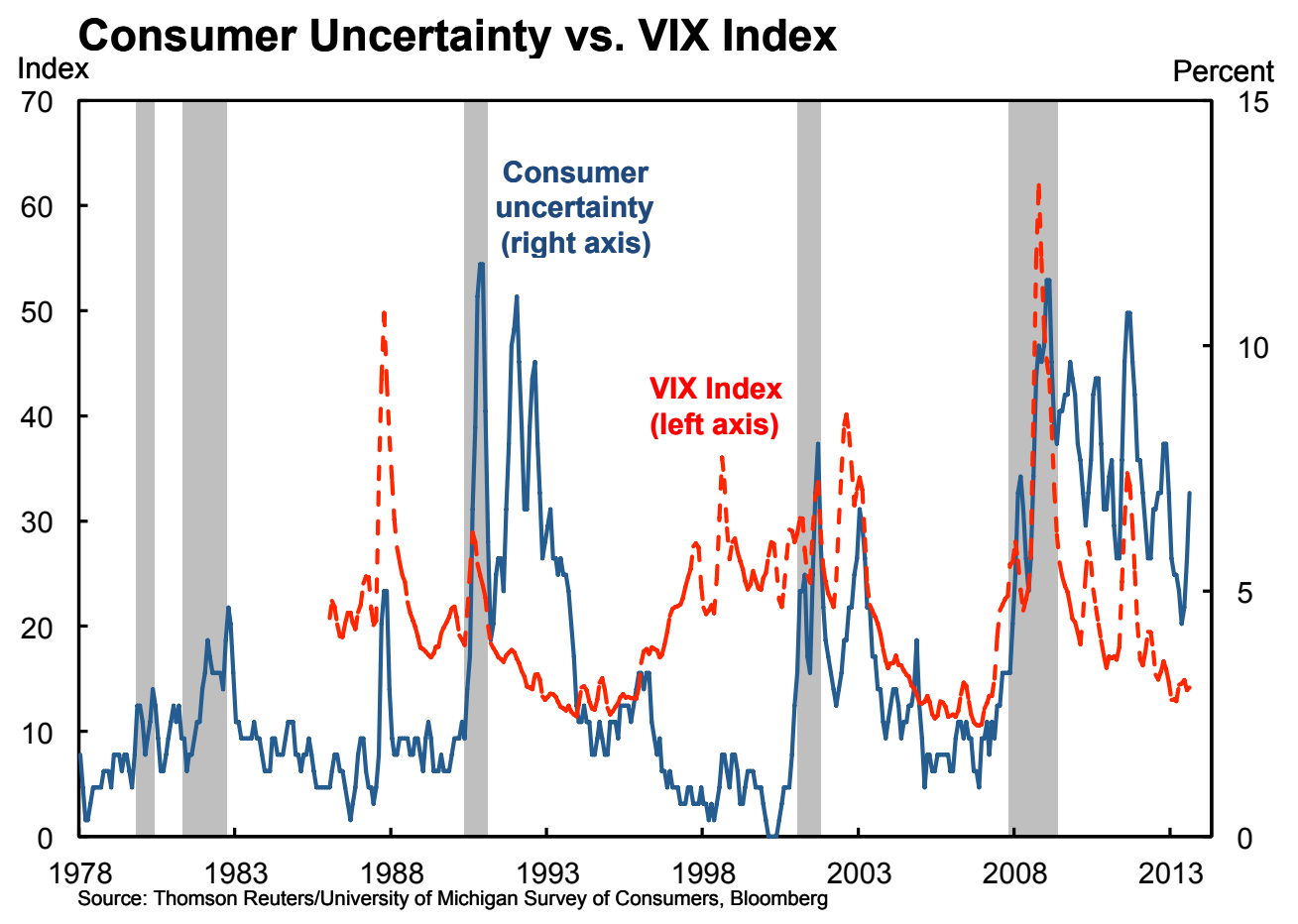

Figure 1. Consumers' perceived uncertainty from the Michigan Survey of Consumers in the United States (solid line) versus the VIX/VXO index from the Chicago Board of Exchange (dashed line). The grey shaded areas indicate NBER recession dates in the United States. Data frequencies are monthly. The consumer uncertainty series starts in January 1978 and the VIX/VXO series starts in January 1986. Both series end by October 2013. Three-month moving averages are plotted. 

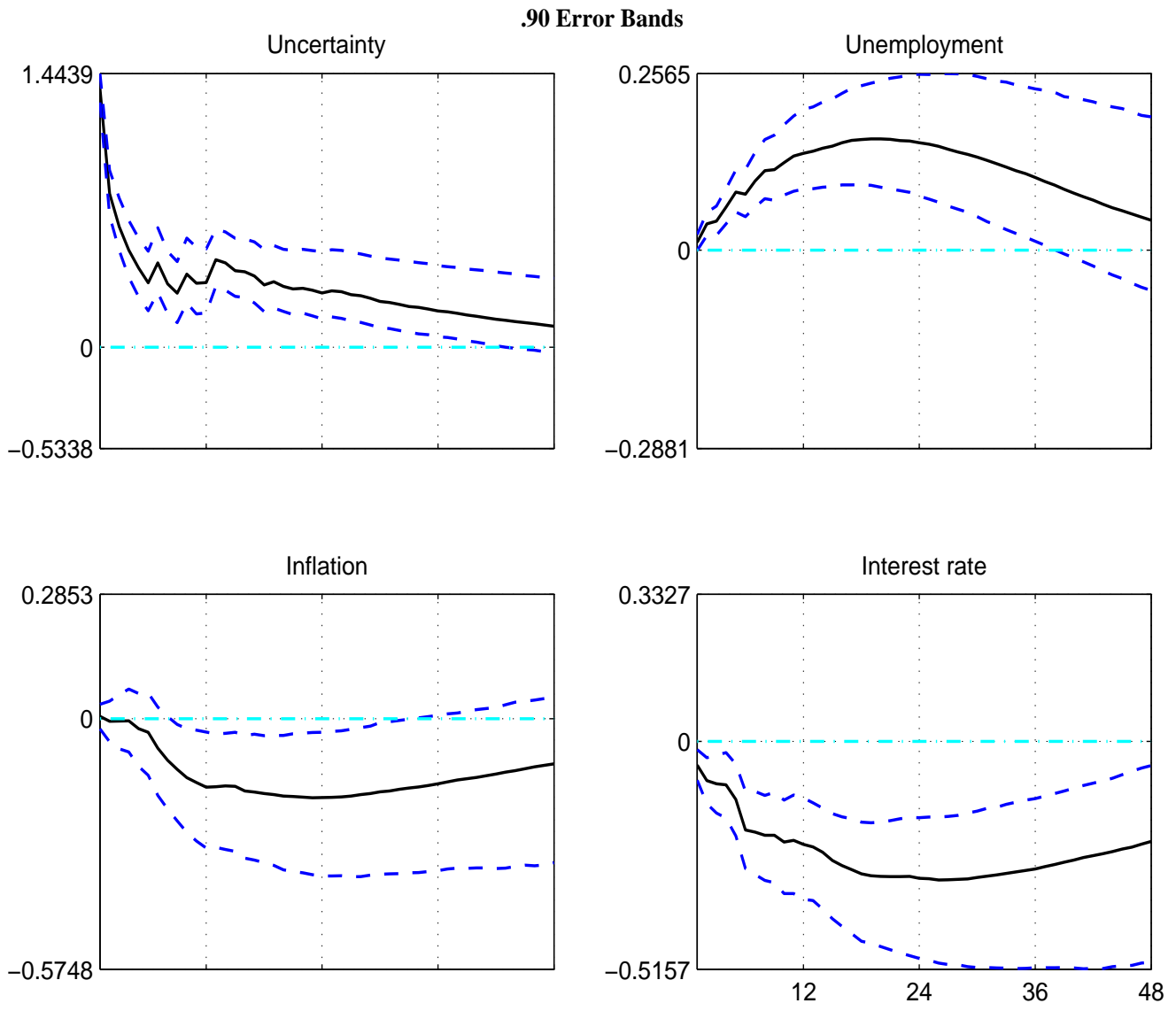

FIGURE 2. The effects of a one-standard deviation shock to perceived uncertainty in the Michigan Survey of Consumers: uncertainty measure ordered first. The solid lines represent median responses of the variables to a onestandard-deviation increase in the innovations to uncertainty. The dashed lines around each solid line represent the 90-percent error bands for the estimated median impulse responses. The units of the horizontal axes are months. The units of the vertical axes are percentage points. 

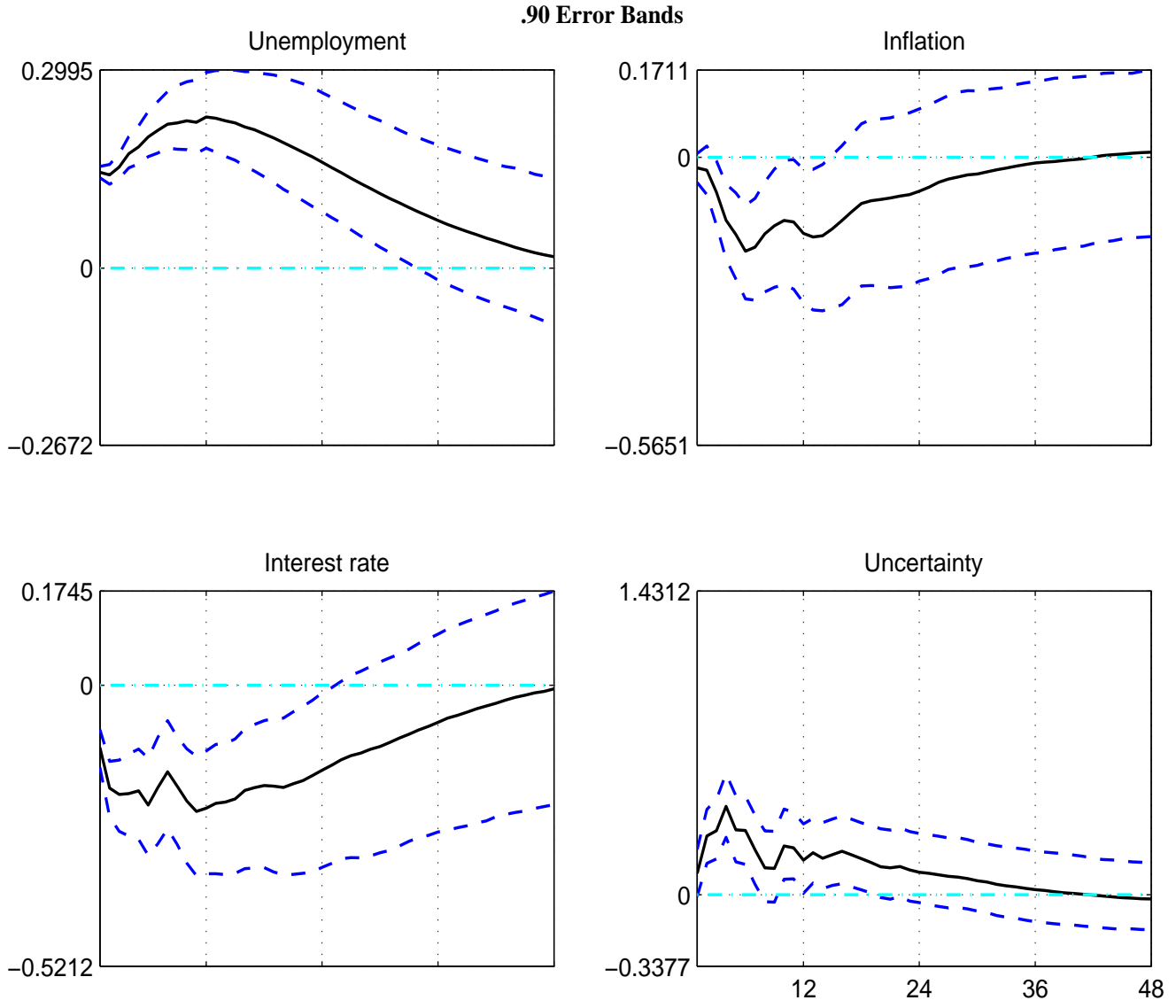

Figure 3. The effects of a one-standard deviation shock to perceived uncertainty in the Michigan Survey of Consumers: uncertainty measure ordered last. The solid lines represent median responses of the variables to a one-standarddeviation increase in the innovations to uncertainty. The dashed lines around each solid line represent the 90-percent error bands for the estimated median impulse responses. The units of the horizontal axes are months. The units of the vertical axes are percentage points. 

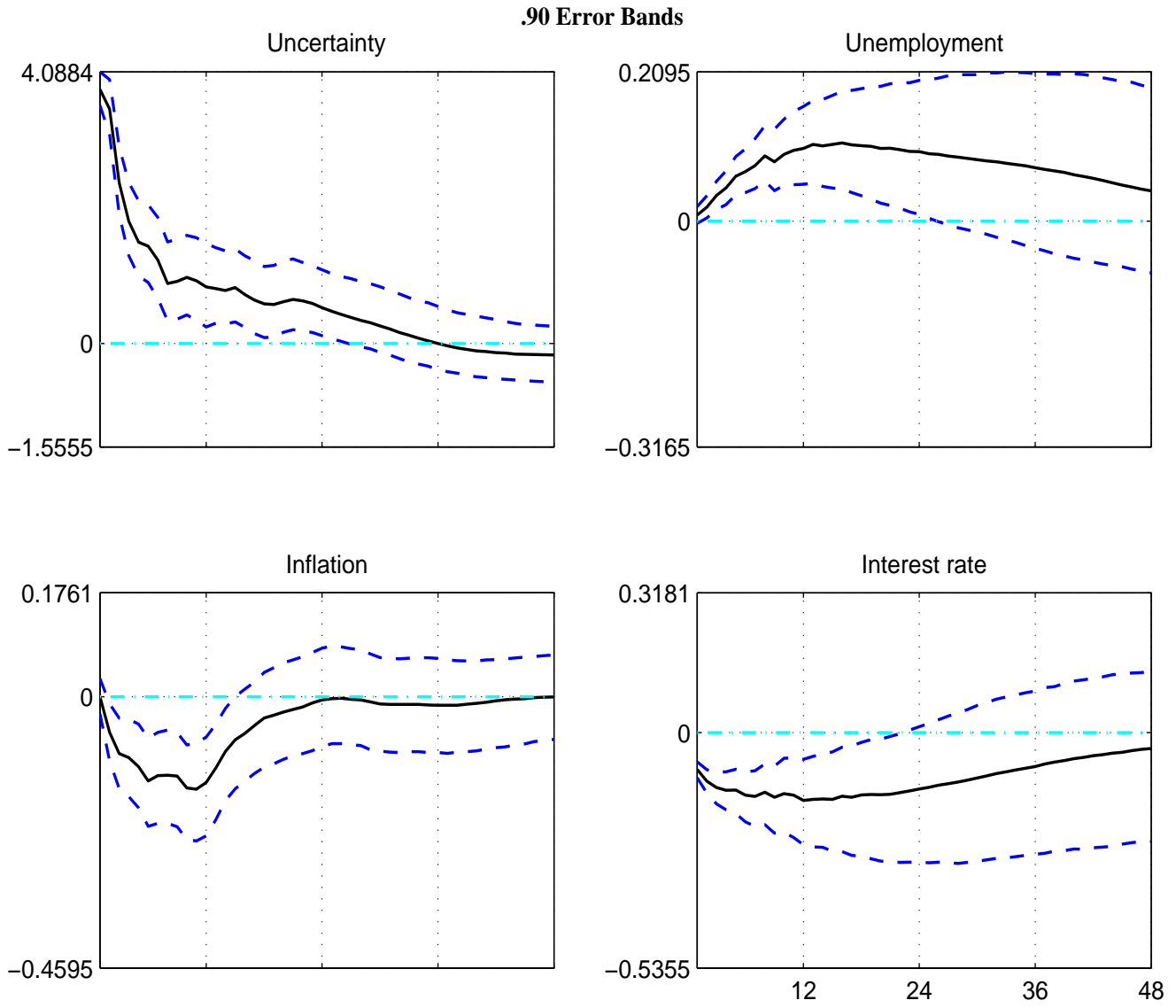

FiguRE 4. The effects of a one-standard deviation shock to the VIX. The solid lines represent median responses of the variables to a one-standard-deviation increase in the innovations to uncertainty. The dashed lines around each solid line represent the 90-percent error bands for the estimated median impulse responses. The units of the horizontal axes are months. The units of the vertical axes are percentage points. 

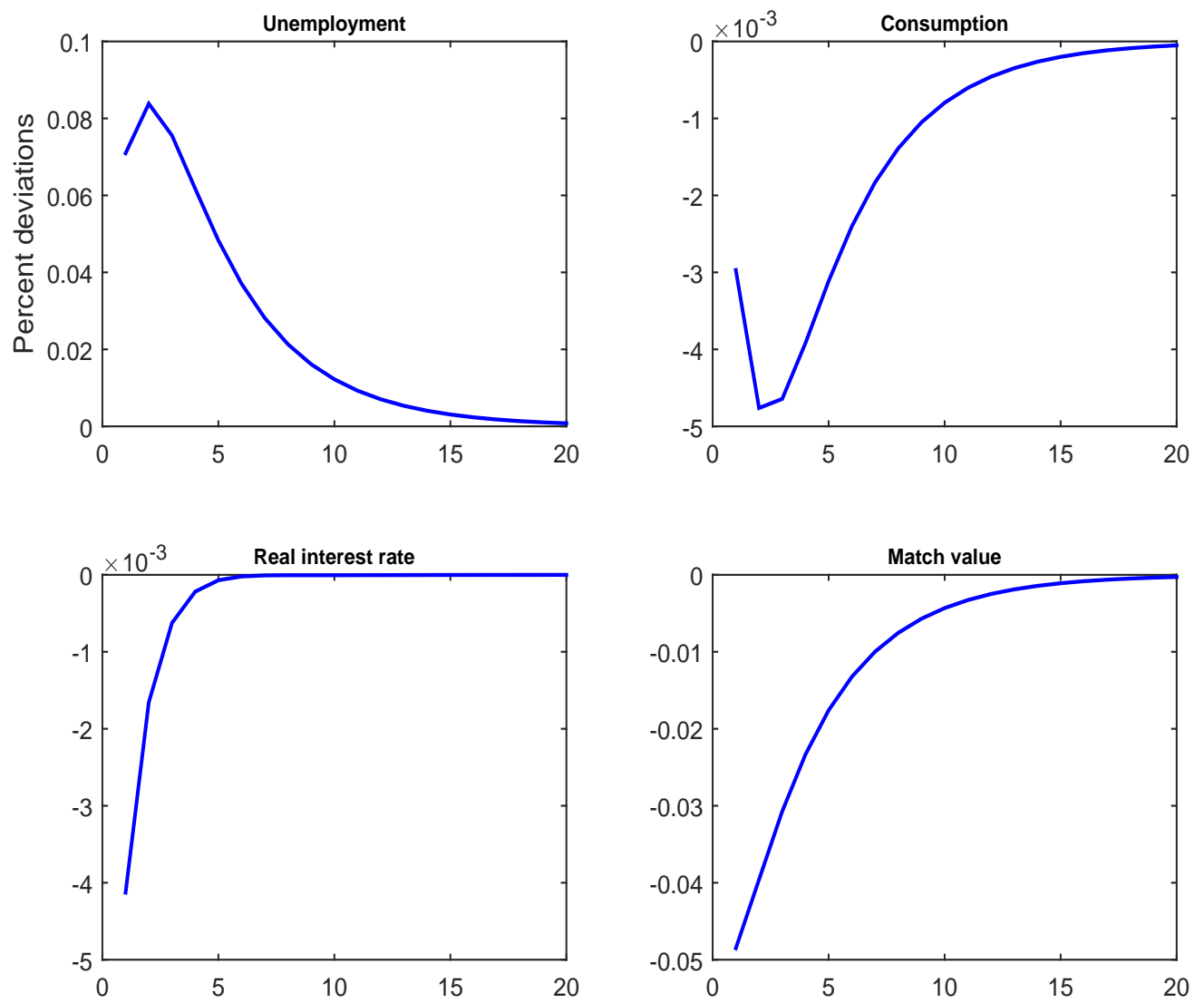

FIGURE 5. Impulse responses to a technology uncertainty shock in the DSGE model with flexible prices. 

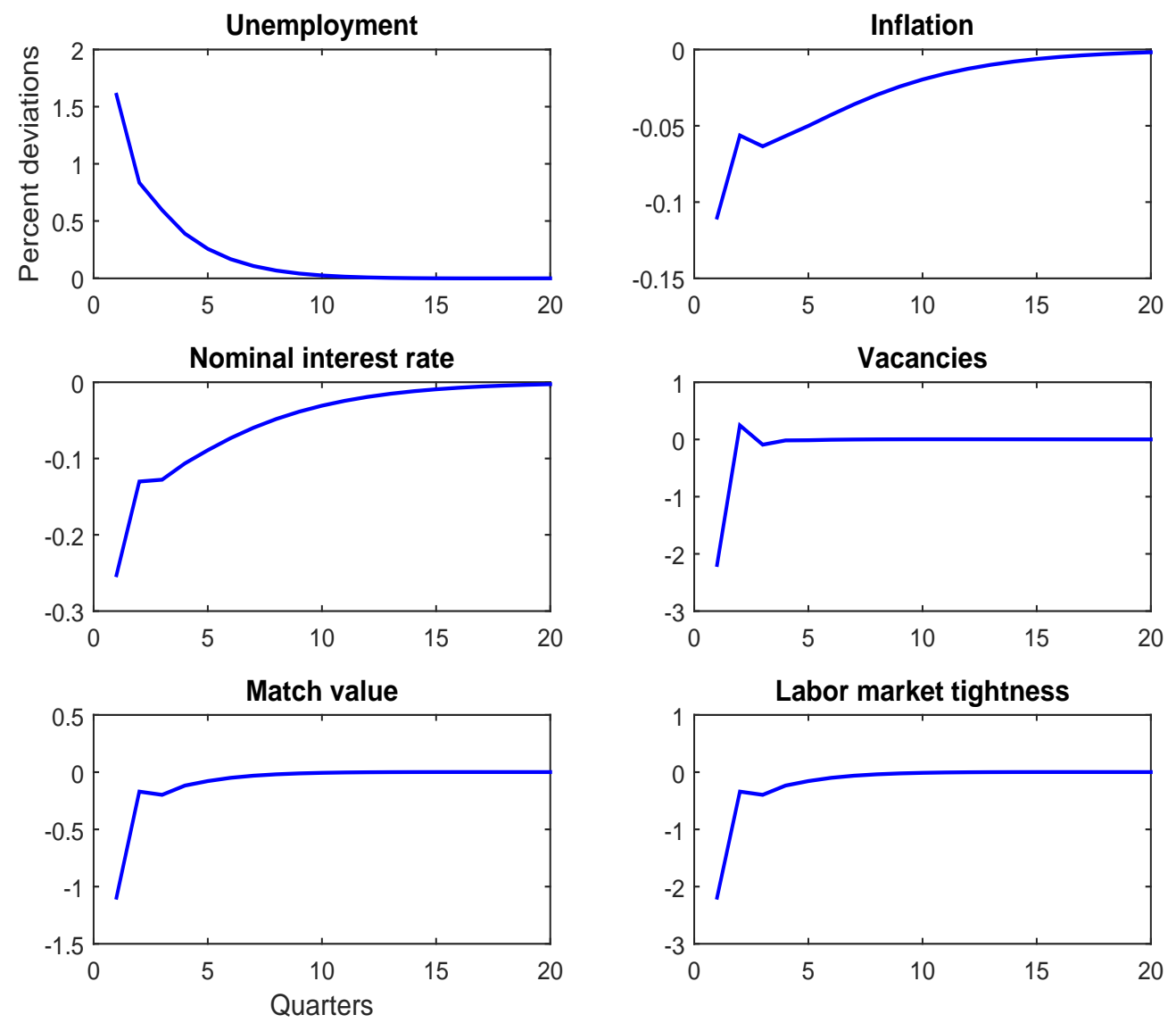

FiguRE 6. Impulse responses of macroeconomic variables to a technology uncertainty shock in the DSGE model with sticky prices. 


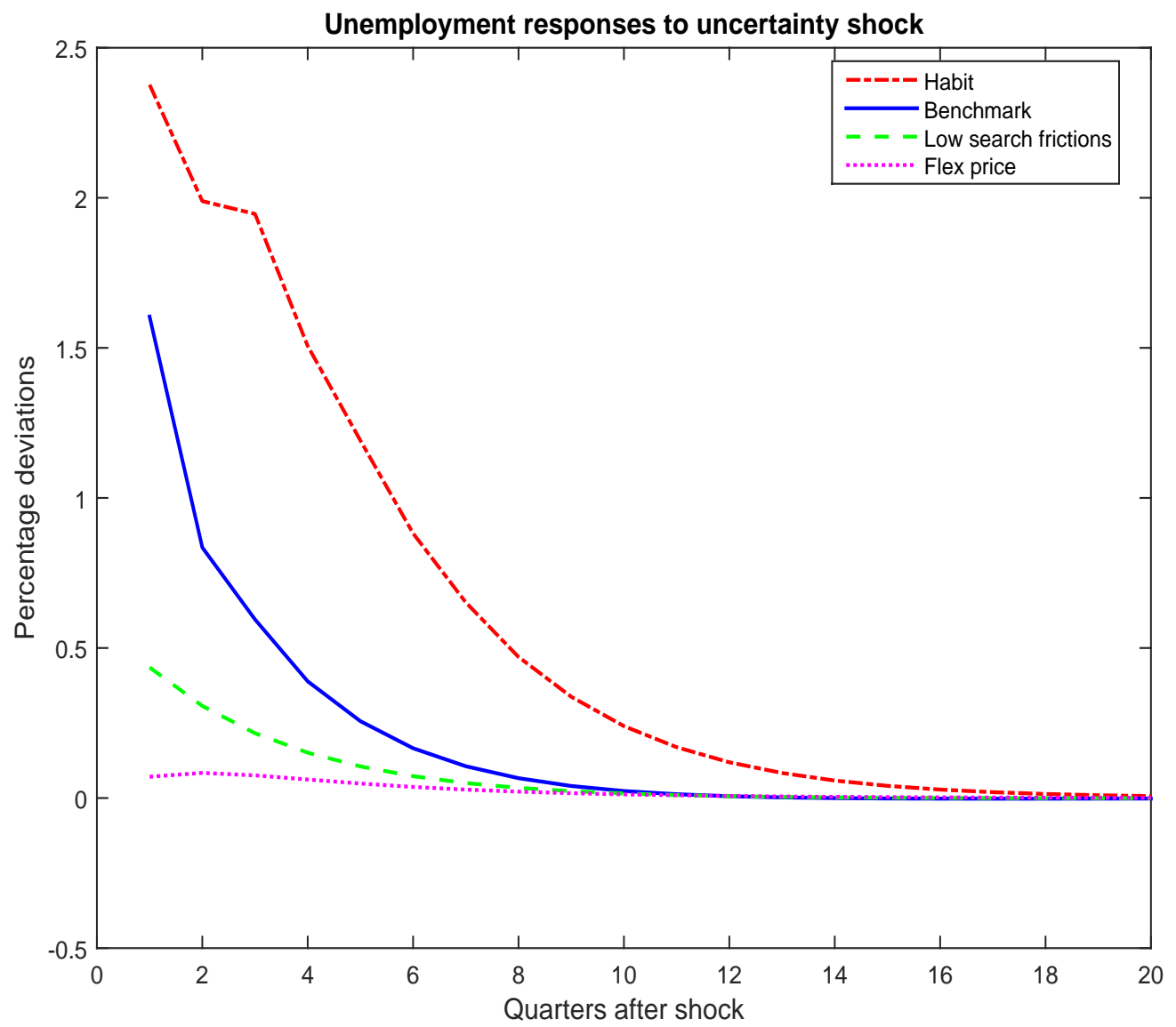

FiguRE 7. Amplification mechanisms for technology uncertainty. 


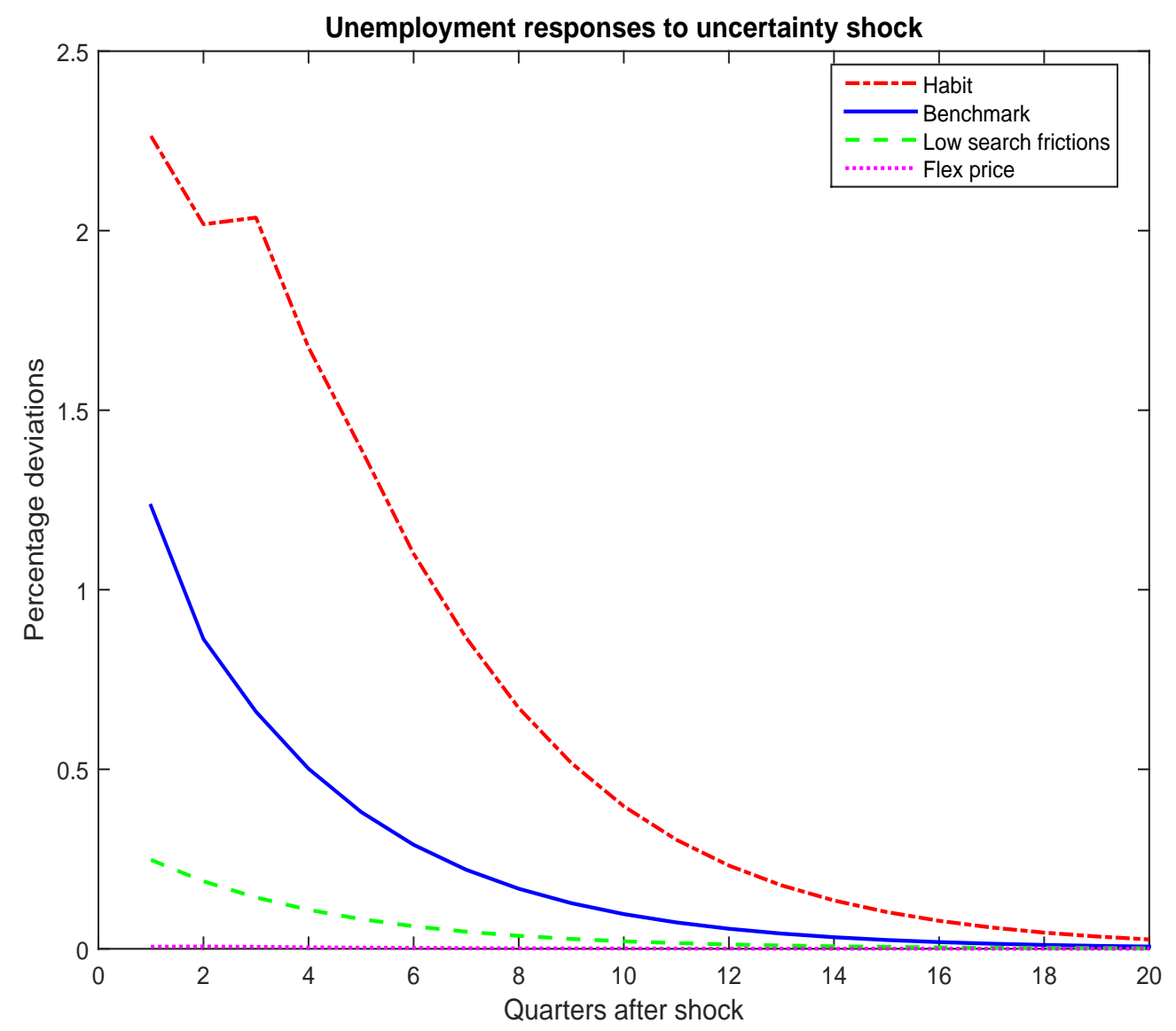

Figure 8. Amplification mechanisms for technology uncertainty in the model with no real wage rigidities. 